\title{
Field work supervision through open and distance learning: an Indian perspective
}

\author{
Sayantani Guin \\ School of Social Work, Indira Gandhi National Open University, New Delhi, India
}

\begin{abstract}
Purpose - The purpose of this paper is to highlight the method of field work supervision in BSW and MSW programmes offered through open and distance learning (ODL) at the Indira Gandhi National Open University (IGNOU). The key argument of the paper will focus on the fact that despite various challenges, field work supervision through ODL provides lot of scope and flexibility to students, generating a cadre of trained social work professionals.

Design/methodology/approach - The paper adopts a case study approach in presenting the various methods employed for field work supervision by the University. This section will highlight the achievements in terms of developing indigenous theory course and the best practices adopted by IGNOU to train social work professionals through adequate and timely supervision in the ODL mode.

Findings - Field work supervision in the ODL mode poses many challenges, especially when compared to that in the conventional universities. Some of these include irregular meeting of supervisor and student, inability of students to meet supervisor due to several reasons like remote location, poor economic background, lack of leave for working professionals, etc.

Research limitations/implications - There is a need for developing a mechanism to regularly orient field work supervisors in supervising students in the ODL mode. It is recommended that regular field work practicum workshops be conducted for supervisors and students. Viva for field work could be made mandatory at different regional centres. Field work supervision could be enhanced through the use of technology, namely, Skype, e-mail, WhatsApp, etc.

Originality/value - The paper describes the various nuances of field work supervision through ODL system. It is an original work and is of great value in understanding the challenges and difficulties encountered by learners and academic counsellors throughout the process of supervision. The paper highlights important recommendations by the stakeholders themselves in mitigating the challenges faced during field work supervision through ODL.
\end{abstract}

Keywords MSW, BSW, Field work supervision, Social work programmes,

Open and distance education (ODE)

Paper type Case study

\section{Introduction}

Supervision of field work is an integral component in social work education. As field work is the core in social work training, similarly field work supervision is the core of effective field work practice. Supervision literally means "to oversee". It is an interactive process between the supervisor and the supervisee and the effectiveness of supervision is highly dependent on the quality of relationship between the supervisor and supervisee (Cohen and Laufer, 1999). In conventional mode of teaching, the face-to-face component of supervision is common. However, this aspect becomes a challenge when social work is offered through the open and distance learning (ODL) mode.

Globally many universities like Florida State University (USA), Charles Sturt University, Australia, Cleveland State University and the University of Akron offer social work

(C) Sayantani Guin. Published in Asian Association of Open Universities Journal. Published by Emerald Publishing Limited. This article is published under the Creative Commons Attribution (CC BY 4.0) licence. Anyone may reproduce, distribute, translate and create derivative works of this article (for both commercial and non-commercial purposes), subject to full attribution to the original publication and authors. The full terms of this licence may be seen at http://creativecommons.org/licences/by/4.0/legalcode
Field work supervision through ODL

Received 16 August 2019 Accepted 2 October 2019

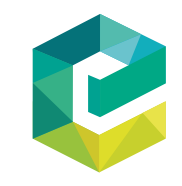

Asian Association of Open Universities Journal Vol. 14 No. 2, 2019 pp. $107-121$

Emerald Publishing Limited DOI 10.1108/AAOUJ-08-2019-0031 
AAOUJ

14,2

108

programmes through ODL. In ODL, since the supervisors and learners are at a distance, many of these universities have adopted the use of information and communication technology (ICT). For instance, at Florida State University, the learners are given online instruction by the faculty members and are helped during their internship by local field advisors. At Charles Sturt University, the programme is offered at distance by the use of ICT through the regional centres of the university. The learners are supervised by the university staff, and, where possible, the university contracts out field visits to local universities or senior social workers. Cleveland State University and the University of Akron, jointly offer social work programmes in the distance mode. The supervision of field practicum is done by the faculty, while administration is handled by field education coordinators at each site (Aara, 2012).

In India, the School of Social Work (SOSW) at Indira Gandhi National Open University (IGNOU) offers social work programmes (BSW, MSW and MSW Counselling) through the ODL mode. The SOSW was established on 16 August 2007 with the approval of the President of India (Thomas, 2015). The School aims to provide quality education in the areas of social work, family studies and tribal studies. The School is currently offering eight programmes of study in social work leading to various certificate, diploma and degree programmes. It started with offering bachelor degree in social work in 2004. Currently MSW and MSW (Counselling) courses are also offered through ODL. On an average, over 30,000 students currently pursue these programmes from within India and 12 countries from India's neighbourhood and African continent. The School is the first in India in offering social work in ODL system and to take social work education to all the states and union territories in the country. It is the first school to have developed high-quality selfinstructional material indigenously (www.ignou.ac.in/ignou/aboutignou/school/sosw/ introduction). Apart from reaching the unreached, IGNOU has developed indigenous literature on social work.

Especially for field work supervision, a separate course titled, "Social Work Practicum and Supervision" at the MSW level is offered, and a "Practitioners Guide" for the field work supervisors (FWS) is provided. The social work programmes are offered through regional centres located in various states in the country. During application to a particular programme of study, students can choose the regional centre of their choice. The regional centre allots a study centre, operational under it and where the respective social work programme is activated. For field work practicum, study centres allot FWS to the students under whose guidance students complete the field work. The minimum qualification of an FWS is master's degree in social work. Supervisors are approved by the faculty of SOSW.

This paper presents the mechanism of field work supervision offered to the learners registered for social work programmes at IGNOU. It critically analyses the achievements and best practices adopted by IGNOU to provide effective field work supervision to the learners. Finally, the paper explains the challenges of field work supervision in ODL mode and offers recommendations for effective field work supervision.

\section{Review of literature}

Field work supervision is an integral component in social work education. The term supervision has derived from the Latin words - "super" meaning "over" and "vision" meaning "to see". Thus the word supervision means "to oversee" (Fehmerling, 2013 as cited in Magnussen, 2018). A definition given by Itzhaky (2000) explains supervision as a helping process in which a skilled person (supervisor) helps a less skilled person (supervisee) with ideas and theoretical knowledge with the practice of which clients are enabled to receive highest quality service (Karpetis, 2010). Internationally, several official reports, journal articles and practice texts emphasize the importance of supervision in professional social work practice (O’Donoghue, 2015). 
Field work with some supervision and guidance was the only source of learning during the training of apprenticeship offered by the Charity Organization Society (Kadushin and Harkness, 2002; Tsui, 2005). The origin of supervision is traced back to late nineteenth century in the USA in voluntary organizations (Magnussen, 2018). During this period, supervision was more of a "apprenticeship" where more experienced supervisors trained new, less experienced volunteers (Fehmerling, 2013 as cited in Magnussen, 2018). Throughout the first half of twentieth century, the concept of supervision expanded to welfare programmes serving both as an internal control measure for public sector social workers and as a criteria for professional growth (Byriel and Damgaard, 1999; Fehmerling, 2013 as cited in Magnussen, 2018). During the 1960s and 1970s, supervision became more of a supportive nature including psychological, treatment oriented understanding (Fehmerling, 2013 as cited in Magnussen, 2018). Presently supervision is firmly established in social work practice.

Field learning through social work practicum enables students to develop specific skills using individual approaches and socio cultural learning approaches (Papouli, 2014). Senge (1990) explains the process of adult learning in social work placements. Sandy Sieminski and Janet Seden (2011) explain how student overcome barriers during field work training and gain confidence. The student-centred teaching methods in social work education, namely, role play, case studies, group exercises and personal reflective activities enable them to draw on their own experiences and integrate them with the insights of others. The component of research dissertation in social work discipline helps in developing analytical problem solving and skills for conducting independent research (Offat and Zvidzai, 2013).

However, learning in social work practice is only effective if it is done under supervision. The outcome of the social work practice depends on how well the supervisor initiates the dialogue and the supervisee receives the supervision (Schulman, 2005). The relationship between a supervisor and supervisee has been termed as a "working alliance" (Mackrill, 2011 cited in Magnussen, 2018) and a "working relationship" based on rapport, trust and caring (Schulman, 2005 cited in Magnussen, 2018).

Magnussen (2018) mentions that the literature on supervision mostly comprises of understanding ontology and epistemology of supervision, theoretical insights on good practice of supervision to achieve best results and methodology books based on authors experiences. In international literature, the purpose of supervision has been accepted to support social workers, and to develop and govern social work (Magnussen, 2018).

Field work supervision in the ODL mode can face several challenges. The findings from a study conducted by Chen et al. (2018) highlight lack of designated time for supervision. Also a clear structure and formal supervision specifying "when, where, who and how much" are missing. A lack of professional supervision highlighting the importance of social work perspective in problem solving, task planning and implementation is also highlighted (Chen et al., 2018). Lack of effective field work practice and supervision leads to lack of competency in doing work in the field (Dash and Botcha, 2018). Other issues related to field work supervision are allocation of supervisors, less qualified supervisors (Bukaliya, 2012), the quality and frequency of feedback (Heeralal, 2015) and students not consulting regularly (Mafa and Mapolisa, 2012).

\section{Methodology adopted to conduct the study}

The study adopted a qualitative research methodology where content analysis and case study methods were adopted. Content analysis of programme guides and all field work practicum journals of BSW, MSW, MSWC programmes of IGNOU was conducted. Data were analysed using coding categories, which were derived directly from the text data. Table I shows the number of books used for content analysis. 
AAOUJ 14,2

110
In order to understand the importance of supervision in field work and challenges faced by students during field work, ten case studies of students were conducted during field work practicum workshops organized at ten different regional centres across the country, namely, Srinagar, Patna, Siliguri, Chennai, Bhopal, Jabalpur, Ranchi, Imphal, Kochin and Bhubaneswar.

\section{Findings}

Field work practicum in social work education through ODL at IGNOU

Field work is an integral part in the BSW, MSW and MSW (Counselling) programmes offered by SOSW at IGNOU. Field work practicum comprises of 40-50 per cent of the total weightage in all the programmes of study in social work. IGNOU has gone beyond the minimum standard of 33-40 per cent as per the criteria of University Grants Commission (Dash and Botcha, 2018; Thomas, 2015). Each student is provided with a field work practicum journal where he/she needs to record his learnings/activities during field work. The student is required to read the instructions given in the journal before proceeding to write the journal. Nevertheless, it is mandatory for every student to be guided by a professional qualified supervisor having post-graduation in social work.

BSW programme is a three year programme. However, a student in ODL may complete BSW within three to six years. In total, 25 days of field work is mandatory in each of the three years in BSW programme. In ODL, a student in MSW programme may complete the programme within two to five years. In total, 45 days of field work is essential every year in MSW programme. In MSW (C), in the first year, a student has to do 45 days of concurrent field work and 30 days of block placement, and in the second year, one has to complete 45 days of concurrent field work and 30 days of internship.

Apart from the printed self-learning materials, separate field work journals have been prepared for each programme. The field work journal is a separate book comprising of various sections. The first section explains the objectives, guidelines and target of field work for each year. The next section provides space for the student to write field work reports for the different activities conducted during the field visits meant for different years. Furthermore, the practitioners guide and the programme guide provide a detailed description on field work to help both the student and the supervisor.

\section{Salient features of field work practicum in IGNOU}

Keeping in mind a diverse student population, SOSW has incorporated a number of strategies to train students in learning various social work practice methodologies:

(1) Compulsory attendance: 100 per cent attendance is mandatory in field work. All components of the field work have to be completed after visiting the agency/ organization. Attendance is also mandatory for a minimum of five individual conferences (IC) and five group conferences (GC).

Table I.

Description of content analysis
Name of book used for content analysis

Number

\begin{tabular}{llr}
\hline S. No. & Name of book used for content analysis & Number \\
\hline 1. & Programme Guide of BSW & 1 \\
2. & Programme Guide of $M S W$ & 1 \\
3. & Programme Guide of $M S W C$ & 1 \\
4. & Field Work Practicum Journal of BSW & 3 \\
5. & Field Work Practicum Journal of $M S W$ & 2 \\
6. & Field Work Practicum Journal of $M S W C$ & 4 \\
& Total & 12
\end{tabular}


(2) Sequential learning: In MSW, a student has to complete the first year of field work before proceeding to finish the second year. During the first year of MSW, students are trained for generalist social work practice in a wide variety of fields ranging from rural and urban community development, schools, corporate settings, nongovernmental organizations, etc., in their 45 days visit to the field. During the second year of field work, the student has to visit another 45 days in the field and get oriented to the six methods of social work, namely, case work, group work, community organization, social action, social welfare organization and social work research (Thomas and Kumari, 2009a, b).

In BSW, each year the student has to visit the field for 25 days. In the first year, the student equips him/herself with the generalist social work practice. In BSW second year, during the 25 days field work, apart from the regular tasks assigned by the agency, the student has to do case work and group work. The field work recording should include the records of the 25 days concurrent visit and also case work and group work activities undertaken by the student. In the third year of BSW, during the 25 days of field work, the student has to undertake community development, social welfare administration, social work research and social action. The journal explains each of the components by giving appropriate examples of each of these methods. The students are expected to read these in detail, follow the guidelines, discuss with the supervisor and practice these methods during the field work (Thomas and Varghese, 2004, 2005, 2006).

In MSW (Counselling), during the 45 days of field work and five orientation visits, the student is equipped to work in social and welfare agencies focussing on different aspects such as open community, institution, health, education, correctional setting, etc. Apart from concurrent field work, the student has to complete a one month block placement and practice any one or two methods of social work. During the second year of MSW (C), the student has to conduct two orientation visits and 45 days in any one organization/institution/social welfare agency and practice case work and record minimum five cases. Apart from 45 days concurrent visit, the student has to do a 30 days of internship during the second year and practice social welfare organization.

Thus, the field work is designed in such a manner that the student is gradually introduced to the nuances of field work practice in social work. All the field work happens under guidance of an MSW qualified FWS (Thomas and Ramya, 2014a, b, c, d, e).

(3) Clearly specified components of field practicum: All components of field work practicum are clearly specified in the journals for the benefit of the students and the field work. The various components of field work are orientation visits, placement, agency-client relationship, assignment of tasks, nature of social work process (activities), team work, administrative assignments, recording and field instruction.

(4) Field work journals: Field work journals are provided to the students which are printed books containing instructions and guidelines for conducting field work for that particular year. The journals also provide space to write the report in the respective sections. Performa for writing reports of orientation visits and concurrent field visits and examples of writing case work or group work are one of the unique features of journals.

(5) Field work manual for supervisors: FWS are provided with a manual called "Practitioner's Guide" that includes guidelines for supervising students' and evaluating students based on their performance and records (Thomas and Kumari, 2010). 
AAOUJ

14,2

(6) "Doorstep" learning: Students are given option to do field work in their own communities. This enables students from far flung areas to opt for the course and complete field work. Students from closed communities like those in prisons can also do field work in their setting. This is in tune with the philosophy of distance education.

Guidelines for social work students regarding field work

The following guidelines are given to the students regarding field work practicum (Ghosh and Kurian, 2016):

(1) At the outset, students are advised to take both the theory and field work seriously. Students are explained that both theory and field work are given equal weightage, i.e. 50 per cent. Also, unless a student completes first year field work, he/she will be unable to do the second and third year field work.

(2) It is reiterated that field work in social work is a learning process and not something equivalent to Socially Useful Productive Work or National Service Scheme. Also, students are not expected to do social service or bring about any radical change in the society.

(3) Activities and programmes should be planned by keeping one's own limitations in mind. As student social worker, one will be visiting the agency/community once or twice a week. So, frequent meetings or long term programmes may not be possible.

(4) Students should also keep in mind the limitations of the agency and accept those limitations. Limitations may include lack of funds, lack of personnel, lack of motivation, lack of infrastructure, poor leadership, poor relationship with community, corruption, etc. Students are required to discuss these issues with the supervisor and take guidance regarding field work.

(5) The field work journal should be used meaningfully and used as a guide to do the field work. At the beginning of the field work, students should formulate a learning plan based on the field work situation and the field work objectives of the particular year, along with the supervisor. The learning plan should have specific tasks for field work. At the end of each field work, the student has to evaluate whether the objectives have been achieved.

(6) Attendance has to be for full day and leaves have to be compensated by doing field work in holidays, with prior permission of FWS.

(7) Attendance for IC and GC is also compulsory. Conference should not be vague discussions on social work topics but should be specific to problems faced in field work. A student has to attend a minimum of five ICs and five GCs during the tenure of field work of that particular year.

\section{Components of field work through ODL}

There are nine components of field practicum in social work which are designed in the SOSW at IGNOU. The nine components are common in all the programmes, however, specific requirements are explained below (Ghosh and Kurian, 2016):

(1) Orientation visits: Orientation visits provide first hand exposure of the student to the field work component in social work training. The students coming from different backgrounds get exposed to the functioning of the agency and the various ways the functionaries are engaged for working with the poorest of the poor and the marginalized sections of the society. Orientation visits are conducted in five 
agencies/institutions. The nature of agencies is specified, namely, health setting hospitals, community health centres, primary health centres, clinics, etc.; correctional settings, civic administration, educational settings, home for the destitute, disaster affected, refugees and migrants, homes for women, children, beggars, elderly, community settings, de-addiction and rehabilitation centres, etc. A detailed proforma serves as a guideline for orientation visit.

(2) Placement: Field work placement is the major component of social work practicum where the students physically visit the agency/organization/field work setting for a required number of days. Usually for BSW, it is 25 days per year, for MSW and MSW (C), it is 45 days per year. Students are placed in groups of three to six in order to understand the essence of team work. Some students who may be working are allowed to do their field work in the same agency, but they have to change their agencies in the subsequent years of field work. FWS are trained to place students according to their interest and locally available resources and community settings. Specific instructions relating to the objectives and tasks of field work are explained in the journal. A proforma mentioning the tasks to be accomplished per day is explained in the journal. A student is expected to gain experience regarding the various programmes/activities of the agency and learn to apply the social work skills and principles during the field work.

(3) Agency client system: Social work practice aims to facilitate effective social functioning of the client. It is with this objective that meaningful relationship has to be established with the client and the agency. Clients may approach the agency themselves or they may be referred by others. Occasionally clients are motivated to approach the agency as a result of some awareness programme conducted by the agency itself. The role of the agency is to facilitate the client by referring to the social worker and providing necessary resources. The student social worker tries to understand the relationship between the agency and the client-individual, group, community, etc. The student is exposed to the major activities of the agency, the target groups, the stakeholders and the facilities utilized to solve the clients' problem.

(4) Assignment of tasks: Tasks are the initial preparations required for initiating an activity. These may be rudimentary in nature and may not be related to social work. The need of the target group and the resources available enable the choice of tasks. Some of the tasks may include meeting individuals and groups to arrange a meeting, interacting with them and enabling them to plan the task and implement it.

(5) Nature of social work process: This component enables students to take up activities and the processes involved in implementing those activities. Emphasis is given on the process of learning of the student in planning and initiating activities, implementing and evaluating them. Students are encouraged to analyse social processes like cooperation, conflict, association and resistance. The various processes required to practice methods of social work are also noted by the students.

(6) Team work: Social worker has to work in teams. Team members may be a person from the same profession, but they may also be from some other professions, namely, doctors, nurses, lawyers, correctional administrators, etc. It is a common observation that a social worker is marginalized among a group of other professionals. The role of social worker is to adjust to the various approaches of team workers and integrate them in order to enable effective problem solving of the client. This component of field work equips the student in explaining their role as part of the team and analyzing the impact of the functioning of the team on the implementation of the programmes. 
AAOUJ

14,2

114

(7) Administrative assignments: Administrative assignments are the inevitable component of any profession. Students have to understand the agency, its objectives, programmes, policies, rules and regulations. During field work, students have to learn official letter writing, maintain records and understand basic statistics regarding income and expenditure.

(8) Recording: Recording is an important aspect of field work training. It helps in maintaining progress of the work, facilitate consultation and evaluate one's performance. The field work journal provided to the students explains the format for recording.

(9) Field instruction expected: This component enables the student to record their guidance they require from the FWS. This section enables the supervisor to be clear about the areas on which the student is facing difficulty and seeking guidance.

Supervision and evaluation of field work through $O D L$

Supervision is an important aspect in field work. In fact, without supervision, field work is not considered complete. The importance of supervision is emphasized by appointing academic counsellors and FWS who are trained and have a qualification in MSW/MA in social work from UGC recognized universities and colleges. Persons having such degrees apply in the study centres through the requisite online forms, which through the regional centre is routed to the SOSW through the Regional Services Division at IGNOU headquarters. The applications are scrutinized by the programme coordinator of the respective programme and approvals are sent to the study centre through the designated channels. The faculty are strict to ensure that no person other than those from social work discipline is approved as FWS. It is also observed that there are many institutions which offer social work degrees but do not have a field work component in their curriculum. Persons having social work degree from such institutions are also not approved as FWS.

Supervision of field work through ODL. In ODL, FWS are either people who are already teaching faculty in conventional social work colleges or institution, or they are practitioners in social agencies. Unlike the conventional system, where the student is able to meet the supervisor during the designated days in a week, in ODL, in IGNOU, students are required to meet the supervisor for a minimum of five ICs and five GCs. Supervision is provided during these days. It is also reported that at many study centres, the supervisors provide guidance to students when the students visit the study centres for academic counselling. Students are advised to meet the supervisors after writing few reports. After each report, space is allocated for supervisory comments. The supervisor provides comments after each report and accordingly suggests the next course of action. The student is expected to write the reports of each IC and GC, which is seen by the supervisor during the subsequent meeting. The supervisor is expected to provide global comments regarding the overall performance of the student at the end of field work of that particular year. Supervisors also utilize social media like WhatsApp in mobile phone to keep in touch with students and provide guidance.

Field work evaluation. Field work evaluation is a continuous process. Students are evaluated on the basis of their gained knowledge, learned skills, professional development of self and attitude. The field work journal and the meetings with the supervisor help the supervisor assess the students' performance. The FWS assigns marks out of 50. Faculty in SOSW at IGNOU are the external evaluators who assign marks out of another 50 . The external examiners take into account the overall performance of the student based on the records and the comments of FWS throughout the field work tenure. A student has to individually pass out of 50 marks. 
A pre-term form and a term end self-assessment form are available in the field work journal of BSW and MSW students. These forms consist of a set of questions on various concepts of social work. After a year of field work, students are required to answer the same set of questions and re-examine the changes that have occurred in them in terms of social work skills, knowledge, attitude and development of professional self. However, this exercise does not carry any marks or grade (Ghosh and Kurian, 2016).

It is pertinent to mention here that the key knowledge acquired by learners during field work practicum is as follows:

(1) Understanding the agency's place in the larger social system and its influence on the agency.

(2) Understanding the policies and procedures of the agency, organizational structure and its influence on service delivery.

(3) Application of this knowledge to the field work practice.

(4) Knowledge of the various programmes the agency implements and the nature of beneficiaries.

(5) Identifying different factors in the neighbourhood and the community that affect client system and the problems caused due to that. Understanding of the macro level causes and micro level causes of the problems.

(6) Identifying relevant knowledge that needs to be applied and correlate theory with the social reality, the learner observes in the field.

(7) Locating various service providers in the area to do referral work.

(8) Understanding the roles of self, the supervisor's and the client's in the field work process.

(9) Identification of the sources in the community from where material and non-material resources can be raised.

(10) Understanding the importance of participation of the beneficiaries in the programme and devise method to enhance the same.

(11) Understanding the importance of planning, implementing and evaluation of projects.

The learner also acquires knowledge regarding the community. Many NGOs in India provide community-related services. Some of them specialize in a single activity, e.g. health or education while others provide multiple services. Most of them have social workers working for them. Their major tasks include study and research on various aspects of the community, identifying the felt needs of the people, organizing awareness programmes, mobilizing people, identifying leaders, setting priorities, suggesting alternative means to solve the problems, implementing programmes and evaluating them. The community setting gives the social worker ample opportunities to use the integrated methods of social work and gain experience as a generalist practitioner.

The supervisory link to student's performance and field work outcomes is ensured by regular contact of the student with the FWS at the study centre. Before the beginning of field work, the student meets the supervisor for an induction meeting. In this induction meeting, all students placed under the guidance of the supervisor are given clear instructions regarding the field work practicum and how to complete the practicum. After the induction meeting, the student is accompanied to five different field work agencies to get an overview of the field placement. The supervisor then helps the student choose one
Field work supervision through ODL 
AAOUJ

14,2

agency in which to conduct the field work practicum for the particular year. A learning plan is formulated between the supervisor and the student based on the objectives of field work practicum of the particular year. The learning plan takes into account the time available, the strengths and limitations of the agency, the need of the beneficiaries and other relevant factors influencing the field work process. After the commencement of field work, the student is in regular contact with the supervisor for guidance. Reports for each day of field work are written by the student and submitted to the supervisor for comments. Based on the comments, the student modifies the process of field work and report writing. At the end of the field work, the student has to write elaborately a self-evaluation report based on the knowledge acquired, the skills gained, the development of professional skills and attitude. The student completes all the components of field work journal and submits it to the FWS. The supervisor finally gives marks based on the performance throughout the year.

Field work supervision through ODL: achievements, importance and impact

Field work in social work is expected to integrate theory into practice. In order to streamline field work supervision through the ODL mode, the following measures have been taken by SOSW at IGNOU.

Development of indigenous literature. The SOSW has developed indigenous literature on social work. The School has produced over 200 titles with ISBN numbers and offers over 60 courses on social work, printed both in English and Hindi. The School has produced over 75 video programmes, most of which are available on you tube. Till recently, the School had direct interactive teleconferencing sessions and interactive radio counselling for social work students within India and for the students covered under the Pan African e-network. Especially for field work supervision, a separate course titled, "Social Work Practicum and Supervision" at the MSW level is offered, and a "Practitioners Guide" for the FWS is provided. The "Practitioners Guide" provides in detail the role and tasks of FWS in ODL, the types of supervisory comments, guidelines for agency practice, social work practice skills and guidelines for FWS.

Flexibility in attendance. A student registered for BSW or MSW has flexibility in terms of attendance in field work. Many students enroling are working professionals or are housewives who do not have the flexibility to study within a structured framework. Thus, an ODL student may not be able to do concurrent field work in a specified two days of a week, as is the practice in conventional universities. Although attendance for field work is mandatory, flexibility in terms of attendance is offered in the following ways, with prior permission of the FWS:

(1) a student not able to do field work during specified days may compensate field work during holidays;

(2) if the number of field work to be compensated is less than ten days, student can compensate on days of his/her convenience; and

(3) if the number of field work to be compensated is more than ten days, student needs to complete it as a block placement, i.e. completing the required number of days continuously.

Mandatory meeting with field work supervisor. It is mandatory for an ODL student in social work to meet the FWS for ICs and GCs. Minimum five meetings for ICs and minimum five meetings for GCs have been made mandatory. A student has to ensure that he/she meets the supervisor at least five times for ICs and GCs at the study centre during the tenure of field work of that particular year. Communication with the supervisor through e-mail, mobile phone and WhatsApp group is also encouraged. 
Workshops in field work practicum. Workshops in field work practicum have been conducted at various regional centres throughout the country, at the eastern, western, central and north-east regions, for the academic counsellors, FWS and students. These workshops explained the process of field work through ODL to the FWS and students. These workshops provided a platform to the supervisors and students to share their problems and concerns. Students were satisfied with their supervisor and commended their support in completing the field work on time.

\section{Challenges faced}

It may be said that IGNOU has catered to the educational aspirations of large section of the population. However, field work supervision through ODL faces many challenges.

Non-specified days of meeting with supervisor. Field work supervision is an integral component in social work training and often requires regular communication between the supervisor and the student.

In conventional system, a student has to do field work and attend ICs and GCs on specified days in a week. However, this system is not feasible in the ODL mode due to the following reasons:

(1) long distance between study centre (where the student is required to meet the supervisor) and the residence of student: there are students located in remote areas of the country and to frequently meet the supervisor at the study centre would take lot of time, energy and finance of the student;

(2) economic background of the student: students who are from low economic background are unable to bear the costs of the travel, every week; and

(3) social background of the students: it is not possible for students who are working professionals, housewives and aged to travel to the study centre every week.

Thus, meeting between the supervisor and the supervisee is not structured in terms of time and space, but is quite flexible depending on the convenience of both.

Based on the above scenario, one may argue about the quality of the social work training imparted through ODL mode. However, it is clear that unlike the conventional universities, ODL mode of field work supervision offers flexible learning without diluting the essence of field work training.

Gap between theoretical learning and field work practice. In conventional mode, learning through field work placements occurs concurrently with classroom teaching. Field work is spread throughout the year along with the classroom teaching. However, in ODL, students take up study at their own pace depending on their motivation and objective of taking up the course. It is often observed that students qualify for exams of all three years and yet they are lagging behind in field work practicum, due to several reasons, namely, inability to avail guidance for field work, closure of study centre, migration to a different city for job or marriage, so on and so forth. In such cases, students are advised to finish the field work one at a time.

Unethical practices. FWS are the backbone of social work education through ODL. IGNOU has to depend on their support and cooperation for effective supervision. All supervisors of IGNOU being qualified professionals in reputed academic institutions are expected to maintain certain standards of values and ethics. However, issues such as copying of field work journal, providing high marks to non-deserving students, completing field work without supervision and submitting fake journals are some of the major issues being faced. Such cases are caught during evaluation of journals at the IGNOU headquarters and necessary steps are taken to uphold the quality of field work in social work education. 
AAOUJ

14,2

118

There may also be cases of providing private tuitions for field work by supervisors by charging tuition fees and guidance by non-MSW qualified supervisors. Such practices require being vigilant by the study centre coordinator at the local study centres.

Administrative issues. There are some instances when field work practicum journals are untraceable and lost during transition from the study centre to the headquarters. Also, many times, there are delay in the submission of journals by the study centre to the headquarter. Any such reported cases are sorted out on an individual case-to-case basis. Students are also required to keep a copy of field work journals, which are handy in case of any such loss.

\section{Recommendations}

It is evident that field work is an important component in social work. Be it in conventional mode or ODL mode, the mechanism to practice field work will differ. The following future plan is recommended to overcome the challenges faced by supervisors during field work practicum supervision and to develop the knowledge and expertise of all the field work carried out by the students:

(1) Training of supervisors: There is a need for developing a mechanism to regularly orient FWS in supervising students in the ODL mode. It is recommended that regular field work practicum workshops be conducted for supervisors and students. The various components of field work and the expectations from the learners could be explained with hands on training during these workshops. The workshops could be organized once a month by faculty from the local social work colleges in the local study centre where participation of all the academic counsellors and students would be mandatory. Hands on training on application of social work methods such as case work, group work, community organization, social action, social work research and social welfare administration would be given. The workshop would also include role plays and other activities which could enlighten the students regarding the various components of social work skills, methods and techniques.

(2) Administrative mechanism should be strengthened to allocate FWS to each student immediately after confirmation of admission to the specific programme of study. Schedule of dates concerning field work supervision should be uploaded in the university website and also in the study centre notice boards. Prior message should be sent to students regarding the upcoming field work supervision date through emails, SMS or WhatsApp.

(3) Provision of viva: Viva for field work could be made mandatory at different regional centres after the completion of field work practicum. Viva would ensure that learners complete their practicum under the guidance of supervisor after meeting the supervisor at regular intervals.

(4) Use of technology: Use of technology is an effective mode of communication and supervision may be strengthened with the help of technology. Field work supervision could be enhanced through the use of technology, namely, Skype, e-mail, WhatsApp, etc. WhatsApp group may be created for a specific group of students and discussion on several issues related to field work may take place. To support virtual communication and effective social work practice, it has been reiterated that social workers need to stay updated with communication technologies (Rafferty and Waldman, 2006 as cited in Dash and Botcha, 2018).

(5) Specific supervision guidelines may be developed specifying the time, venue and duration of field work supervision and professional supervision through clearly 
structured supervisory meetings. Guidelines should incorporate use of professional knowledge and skills in assisting students mediating between reality of agency practice and learning of professional content. It should also elaborate the application of social work knowledge and skills in the specific cultural context.

(6) Research studies should be conducted to examine how supervision is happening in the ODL mode, understand the perception of supervisors regarding effective supervision in order to recommend guidelines for consistent supervision. Empirical research studies should also be conducted to examine the indigenization of social work knowledge and micro level practice.

(7) A forum should be created at the University to enable students report on the challenges they face during field work practicum. A continuing dialogue between FWS, students, study centre coordinator, regional centre and university faculty contributes and improves student experience of learning (Sieminski and Seden, 2011).

\section{Conclusion}

The social work profession has now gained wide popularity in terms of job opportunities. More and more candidates are coming forward to take up the course. By offering social work through ODL, the SOSW has reached the unreached. Field work is an important component of the social work programmes especially in BSW, MSW and MSW (Counselling). In conventional universities, it is convenient for students to practice field work due to several reasons such as classroom setting, proximity to teachers, etc. However, in ODL system, practice of field work effectively becomes a challenge. Thus, this paper highlighted the several methods adopted by the SOSW to enable learners practice field work effectively. Provision of self-learning materials, programme guide and field work practicum journals to the students and practitioners guide to the supervisors are some of the techniques employed by IGNOU. The paper also discussed about the method of field work supervision and evaluation that are being employed by the supervisors. Meetings with supervisors are made mandatory and learners have to report the meeting through IC. Regular workshops are also conducted by the School to train the supervisors regarding field work supervision in the ODL mode. The paper highlighted some challenges like non-specified days of meeting with supervisor, administrative issues and unethical practices while supervising students in ODL mode. Finally the paper offered some recommendations to strengthen the field work supervision in the ODL mode.

\section{References}

Aara, R. (2012), "Supervision of social work field practicum in ODL system: an IGNOU model", Indian Journal of Open Learning, Vol. 21 No. 2, pp. 147-153.

Bukaliya, R. (2012), "The potential benefits and challenges of internship programmes in an ODL institution: a case for the Zimbabwe Open University", International Journal on New Trends in Education and Their Implications, Vol. 3 No. 1, pp. 118-133.

Byriel, C. and Damgaard, I. (1999), Introduktion til Supervision (Introduction to Supervision), Reitzels Forlag, Copenhagen.

Chen, Q., Wu, L. and Peng, T. (2018), "Exploring gaps between MSW students' experiences and expectations of field supervision in a Chinese setting", Social Work Education, Vol. 37 No. 2, pp. 265-276, doi: 10.1080/02615479.2017.1395406.

Cohen, B.-Z. and Laufer, H. (1999), "The influence of supervision on social workers perceptions of their professional competence", The Clinical Supervisor, Vol. 18 No. 2, pp. 39-50, doi: 10.1300/ J001v18n02_03. 
AAOUJ 14,2

Dash, B.M. and Botcha, R. (2018), "Social work education through open and distance learning: an Indian perspective", Turkish Online Journal of Distance Education, Vol. 19 No. 2, pp. 149-165.

Fehmerling, H. (2013), "Supervision (supervision)", in Porsborg, R., Nørrelykke, H. and Antczak, H. (Eds), Socialrådgivning Ogsocialt Arbejde - en Grundbog: Supervision (Social Counselling and Social Work - A Textbook), Socialpædagogisk Bibliotek, Hans Reitzels Forlag, Copenhagen, pp. 531-554.

Ghosh, P.K. and Kurian, A. (2016), Reaching the Unreached with Social Work Education the Gracious Way, Uppal Publishing House, New Delhi.

Heeralal, P.J.H. (2015), "Improving postgraduate supervision in an open and distance learning environment: a case study at the college of education, University of South Africa", South African Journal of Higher Education, Vol. 29 No. 3, pp. 87-100.

Itzhaky, H. (2000), “The secret in supervision”, Families in Society, Vol. 81 No. 5, pp. 529-537.

Kadushin, A. and Harkness, D. (2002), Supervision in Social Work, Columbia University Press, New York, NY.

Karpetis, G. (2010), "Field practice supervision of social work students: a psychodynamic view on the emotional context of the process and the setting during the client assessment phase", European Journal of Social Work, Vol. 13 No. 4, pp. 503-522, doi: 10.1080/13691451003603448.

Mackrill, T. (2011), "Differentiating life goals and therapeutic goals: expanding our understanding of the working alliance", British Journal of Guidance \& Counselling, Vol. 39 No. 1, pp. 25-39.

Mafa, O. and Mapolisa, T. (2012), "Supervisors' experiences in supervising postgraduate education students' dissertations and theses at the Zimbabwe Open University (ZOU)", International Journal of Asian Social Science, Vol. 2 No. 10, pp. 1685-1697.

Magnussen, J. (2018), "Supervision in Denmark - an empirical account of experiences and practices", European Journal of Social Work, Vol. 21 No. 3, pp. 359-373, doi: 10.1080/13691457.2018.1451827.

O'Donoghue, K. (2015), "Issues and challenges facing social work supervision in the twenty-first century", China Journal of Social Work, Vol. 8 No. 2, pp. 136-149, doi: 10.1080/175250 98.2015.1039172.

Offat, M. and Zvidzai, M.J. (2013), "Problems encountered by undergraduate students while conducting research projects: a case study of the Zimbabwe Open University", Indian Journal of Open Learning, Vol. 22 No. 2, pp. 87-105.

Papouli, E. (2014), "Field learning in social work education: implications for educators and instructors", Field Educator, Vol. 4.2, Fall, pp. 1-15.

Rafferty, J. and Waldman, J. (2006), "Fit for virtual social work practice", Journal of Technology in Human Services, Vol. 24 Nos 2-3, pp. 1-22.

Schulman, L. (2005), “The clinical-practitioner working alliance: a parallel process”, Clinical Supervisor, Vol. 24 Nos 1-2, pp. 23-47.

Senge, P. (1990), The Fifth Discipline: The Art and Practice of Learning Organisation, Doubleday, New York, NY.

Sieminski, S. and Seden, J. (2011), "An exploration of how some tutors use learning materials to enable student social workers to link theory to practice while learning in the workplace, social work education”, The International Journal, Vol. 30 No. 7, pp. 797-810, doi: 10.1080/ 02615479.2010 .512658$.

Thomas, G. (2015), "Social work education through distance learning in India”, in Bhatt, S. and Pathare, S. (Eds), Social Work Education and Practice Engagement, Shipra Publications, New Delhi, pp. 66-77.

Thomas, G. and Kumari, N. (2009a), Field Work Journal: MSW (First Year), IGNOU, New Delhi. Thomas, G. and Kumari, N. (2009b), Field Work Journal: MSW (Second Year), IGNOU, New Delhi.

Thomas, G. and Kumari, N. (2010), Social Work Practicum: The Practitioner's Guide, IGNOU, New Delhi. 
Thomas, G. and Ramya, N. (2014a), Social Work Practicum Guide for Students (Block 1), IGNOU, New Delhi. Thomas, G. and Ramya, N. (2014b), Field Work Journal (MSWC) (First Year) (Block 2), IGNOU, New Delhi. Thomas, G. and Ramya, N. (2014c), Block Placement Journal MSW: Couselling (First Year), IGNOU, New Delhi.

Thomas, G. and Ramya, N. (2014d), Field Work Journal (MSWC) (Final Year), IGNOU, New Delhi.

Thomas, G. and Ramya, N. (2014e), Internship Record MSW: Couselling (Second Year), IGNOU, New Delhi. Thomas, G. and Varghese, J. (2004), Field Work Journal: BSW (First Year), IGNOU, New Delhi. Thomas, G. and Varghese, J. (2005), Field Work Journal: BSW (Second Year), IGNOU, New Delhi. Thomas, G. and Varghese, J. (2006), Field Work Journal: BSW (Third Year), IGNOU, New Delhi. Tsui, M. (2005), Social Work Supervision: Context and Concepts, Sage Publications, London.

\section{Corresponding author}

Sayantani Guin can be contacted at: sayantani.guin@gmail.com 